EXTENDED REPORT

\title{
Charles Bonnet syndrome in Asian patients in a tertiary ophthalmic centre
}

\author{
C S H Tan, V S Y Lim, D Y M Ho, E Yeo, B Y Ng, K G Au Eong
}

Br J Ophthalmol 2004;88:1325-1329. doi: 10.1136/bjo.2004.041947

See end of article for authors' affiliations .....................

Correspondence to: Dr C S H Tan, The Eye Institute at Tan Tock Seng Hospital, National Healthcare Group, Tan Tock Seng Hospital, 11 Jalan Tan Tock Seng, Singapore 308433 , Singapore; Colintan_eye@ yahoo.com.sg

Accepted for publication 29 February 2004

\begin{abstract}
Aims: To describe the epidemiology of Charles Bonnet syndrome (CBS) among patients in an Asian tertiary ophthalmic centre and to describe the characteristics of the hallucinations experienced.

Methods: 1077 consecutive patients aged 50 years and above were asked a standardised question to determine if they had ever experienced formed visual hallucinations. All patients who experienced these symptoms were further interviewed using a detailed, standardised questionnaire to ascertain if they met the diagnostic criteria established for CBS.

Results: There were 491 men (45.6\%) and 586 women (54.4\%). The best corrected visual acuity ranged from $20 / 20$ to light perception in the better seeing eye and from $20 / 20$ to no light perception in the worse seeing eye. Four patients $(0.4 \%)$ were diagnosed with CBS; two men and two women. There were two Chinese and two Indians. The average age of the CBS patients was 76.3 years (range 65-90 years). Two patients had cataracts, one had glaucoma, and one had both cataracts and glaucoma. A wide variety of visual hallucinations were reported. Three out of four patients experienced a negative reaction to their hallucinations. Only one patient had discussed his symptoms with a doctor.

Conclusions: This is the first report on the epidemiology of CBS in Asian patients. The prevalence rate of CBS $(0.4 \%)$ is slightly lower than in comparable studies in non-Asian populations. The nature of the hallucinations experienced were similar to those previously reported.
\end{abstract}

standard question to determine if they had ever experienced complex, formed visual hallucinations: "Sometimes people who have eye problems affecting their eyesight see images or hallucinations that are actually not really there or see things that other people don't see. This is a known condition called Charles Bonnet syndrome. It happens to people who are of sound mind and have no mental or psychiatric problems. Have you ever experienced any visual hallucinations?"

All respondents who said "yes" were further interviewed by the main author (CSHT), using a detailed, standardised questionnaire to ascertain if they met the diagnostic criteria established for CBS. The diagnostic criteria used for CBS were presence of complex, formed visual hallucinations with normal insight and mental state examination, and absence of delusions or hallucinations in the other sensory modalities. Patients who experienced concomitant auditory hallucinations were excluded, even if these occurred together with the visual hallucinations. Patients who reported photopsias, floaters and simple patches of colour were excluded as these do not constitute complex hallucinations. The patients' conscious state and general health at the time of the hallucinations were ascertained to differentiate from hypnopompic and hypnogogical hallucinations, hallucinations associated with delirium, or those caused by medications. The Mini-Mental State Examination was used to determine cognition. Patients with dementia or conditions that may cause hallucinations such as a previous or current history of psychiatric illness, epilepsy, organic brain lesions, or drug and alcohol dependence were excluded from this study.

Patients diagnosed with CBS were asked to describe their visual hallucinations experienced in detail (appendix). In addition, patients were asked for their reaction, if any, to these hallucinations. They were also asked if they had

Abbreviations: BCVA, best corrected visual acuity; CBS, Charles Bonnet syndrome 
Table 1 Characteristics of study population $(n=1077)$

\begin{tabular}{|c|c|c|}
\hline & Number & $\%$ \\
\hline \multicolumn{3}{|l|}{ Sex: } \\
\hline Male & 491 & 45.6 \\
\hline Female & 586 & 54.4 \\
\hline \multicolumn{3}{|l|}{ Ethnic groups: } \\
\hline Chinese & 938 & 87.1 \\
\hline Indian & 70 & 6.5 \\
\hline Malay & 52 & 4.8 \\
\hline Others & 17 & 1.6 \\
\hline \multicolumn{3}{|l|}{ Religion: } \\
\hline Buddhists and Taoists & 616 & 57.2 \\
\hline Christians and Catholics & 168 & 15.6 \\
\hline Muslims & 62 & 6.0 \\
\hline Hindus & 45 & 4.2 \\
\hline No religious affiliation & 137 & 12.7 \\
\hline Others & 9 & 0.9 \\
\hline \multicolumn{3}{|l|}{ Ophthalmic diagnosis: } \\
\hline Cataract & 643 & 59.9 \\
\hline Diabetic retinopathy & 148 & 13.8 \\
\hline Glaucoma & 93 & 8.7 \\
\hline Age related macular degeneration & 50 & 4.7 \\
\hline Others & 143 & 13.3 \\
\hline \multicolumn{3}{|c|}{ Best corrected visual acuity (better seeing eye): } \\
\hline $20 / 20-20 / 40$ & 844 & 78.4 \\
\hline $20 / 50-20 / 200$ & 206 & 19.1 \\
\hline Worse than $20 / 200$ & 27 & 2.5 \\
\hline \multicolumn{3}{|c|}{ Best corrected visual acuity (worse seeing eye): } \\
\hline $20 / 20-20 / 40$ & 530 & 49.2 \\
\hline $20 / 50-20 / 200$ & 365 & 33.9 \\
\hline Worse than $20 / 200$ & 182 & 16.9 \\
\hline \multicolumn{3}{|l|}{ Housing type: } \\
\hline Public housing (apartments) & 810 & 86.2 \\
\hline Private condominiums & 53 & 5.6 \\
\hline Private, landed property & 77 & 8.2 \\
\hline
\end{tabular}

previously discussed the hallucinations with anyone and, if so, the reaction of the people spoken to. Those who had not previously discussed their symptoms with anyone were asked the reasons for this.

\section{RESULTS}

A total of 1077 consecutive patients with a mean age of 67.9 years (range 50-104 (SD 8.89)) were screened; 740 of these patients $(68.7 \%)$ were aged 64 years or above. The average number of family members living with the patients was 2.6 (range 0-9 (SD 1.74)). The demographics of the patients screened are summarised in table 1.

Of the 1077 patients screened, four $(0.4 \%)$ were diagnosed with CBS. The average age of the CBS patients was 76.3 years (range 65-90 years). The characteristics of the visual hallucinations experienced and the patients' reactions are listed in table 2.

The four patients reported a wide variety of visual hallucinations including people, animals, flowers, and various inanimate objects such as spectacles, a cup, and handkerchiefs. The images seen were unfamiliar to the patients, meaning that they did not recognise and/or recall that they had ever seen these images before.

Three of the CBS patients experienced a negative reaction to their hallucinations: two were annoyed and the third was initially frightened but had since grown used to it. The fourth patient did not experience any reaction and simply accepted the hallucinations as a consequence of his cataract. None reported any personal meaning in the content of the hallucination.

\section{DISCUSSION}

Since visual hallucinations can be caused by a wide variety of conditions affecting any part of the visual pathway as well as other brain structures, systemic diseases, organic brain pathology, or psychiatric illnesses must be excluded before a diagnosis of CBS can be made.

Several theories have been suggested to explain CBS although heterogeneous and multifactorial causes appear to be the best explanation at present. ${ }^{12}$ Reduced or aberrant visual stimulation appears to be the initiating factor, ${ }^{6}$ which then causes visual hallucinations either by a release phenomenon ${ }^{13}$ or by cortical irritation. Schultz et al proposed that they are the visual analogue of the phantom limb phenomenon. The hallucinations are caused by brain activity in the absence of sensory (visual) input. ${ }^{6}$

Our cross sectional study represents the largest single consecutive group of ophthalmic patients screened for CBS and, to the best of our knowledge, is the first performed in an Asian (non-white) population. Only patients aged 50 and above were screened since many studies have demonstrated that the prevalence rate increases with age, ${ }^{10}$ although it may also affect younger patients, ${ }^{6}{ }^{14}{ }^{15}$ including those in the paediatric age group. ${ }^{16}{ }^{17}$ Interestingly, the average age of patients with CBS ( 76.3 years) in our study was higher than that of the population being screened (67.9 years).

The prevalence of CBS in the few cross sectional studies performed to date ranges from $1 \%$ to $13 \% .^{70^{12} 1819}$ The variation in reported prevalence rate of formed visual hallucinations may partly be explained by the different patient populations screened, which varied from those in general medical ${ }^{9}$ and ophthalmology clinics, ${ }^{10}$ to patients seen in a low vision clinic $^{718}$ and patients with specific ocular pathology. ${ }^{11} 1219$ The prevalence rate of CBS in our study $(0.4 \%)$ is slightly lower than the $1-2 \%$ reported in studies involving patients with generally good visual acuity. ${ }^{9}{ }^{10}$ If we used the same age criteria specified by Tuenisse et $a l^{10}$ and included only patients aged 64 and above, the prevalence rate in our study increases to $0.5 \%$.

The lower prevalence of CBS in our study may be the result of a real difference in the prevalence rates of CBS between Asian and white populations, possibly as a result of genetic differences or structural variation in the eye or visual pathway. It is also possible that some patients who had experienced visual hallucinations chose not to reveal their symptoms to the investigators. Other authors have suggested that the actual prevalence of CBS may be higher than reported because patients may be afraid to reveal their experiences for fear of being labelled a psychiatric case or "mad." 1820 The diagnosis of a psychiatric illness carries a stigma in many cultures. ${ }^{21}$ In a recent survey of psychiatric patients in Singapore, a significant proportion disclosed that the stigma had repercussions on their employment prospects, social interaction, and self esteem. ${ }^{22}$ It is hoped that with increased awareness of CBS among medical professionals and the public, patients will be less hesitant to reveal their symptoms.

In our study, the proportion of males with CBS was $0.41 \%$ compared to $0.34 \%$ in females. Some other studies that have demonstrated no difference between the sexes, ${ }^{10}{ }^{11}$ although a few have found a higher ratio of females to males. ${ }^{6}{ }^{12}$

The prevalence rate of CBS in Chinese patients was $0.21 \%$ compared to $1.44 \%$ in non-Chinese. Because of the rarity of this condition, we are unable to ascertain if a true difference in the prevalence rate exists among the various ethnic groups. Most previous studies have not provided information on the ethnic groups of the cases reported so the variation of prevalence rates among different ethnic groups, if any, is not known. ${ }^{6}$

The average number of family members staying with patients with CBS was lower: 1.5 (range 0-4) compared to 2.6 for the population screened. Some studies have shown that patients living alone ${ }^{911}$ or who reported feeling lonely ${ }^{23}$ were more likely to experience CBS. 
Table 2 Characteristics of patients who experience visual hallucinations

\begin{tabular}{|c|c|c|c|c|}
\hline & Patient 1 & Patient 2 & Patient 3 & Patient 4 \\
\hline Age (years) & 90 & 78 & 72 & 65 \\
\hline Sex & Female & Female & Male & Male \\
\hline Race & Chinese & Chinese & Indian & Indian \\
\hline $\begin{array}{l}\text { Number of family members } \\
\text { staying with patient }\end{array}$ & 0 & 4 & 1 & 1 \\
\hline Ophthalmic diagnoses & $\begin{array}{l}\text { Both eyes: glaucoma, } \\
\text { cataract }\end{array}$ & $\begin{array}{l}\text { Right eye: pseudophakic, } \\
\text { left eye: cataract }\end{array}$ & $\begin{array}{l}\text { Both eyes: glaucoma with } \\
\text { superior arcuate visual field } \\
\text { defect }\end{array}$ & $\begin{array}{l}\text { Right eye: clinically } \\
\text { significant macular } \\
\text { oedema, posterior } \\
\text { capsule opacity, left } \\
\text { eye: cataract }\end{array}$ \\
\hline Visual acuity & $\begin{array}{l}\text { Right eye } 20 / 60 \text {, left } \\
\text { eye hand motion }\end{array}$ & $\begin{array}{l}\text { Right eye } 20 / 100 \text {, } \\
\text { left eye } 20 / 60\end{array}$ & $\begin{array}{l}\text { Right eye } 20 / 30 \text {, } \\
\text { left eye } 20 / 40\end{array}$ & $\begin{array}{l}\text { Right eye } 20 / 60 \text {, } \\
\text { left eye } 20 / 100\end{array}$ \\
\hline Duration of symptoms & 1 year & 2 months & 1.5 years & 1 year \\
\hline Frequency of symptoms & Daily & Daily & Every $2-3$ days & 1-2 times per week \\
\hline Duration of each episode & 5 minutes-1 hour & Seconds & Seconds & 5 minutes \\
\hline Change in frequency of hallucination & Same & Stopped & Increased & Increased \\
\hline Hallucinations & $\begin{array}{l}\text { Children, Indian } \\
\text { worker, corpse }\end{array}$ & $\begin{array}{l}\text { Half body of a handsome } \\
\text { male, flowers }\end{array}$ & $\begin{array}{l}\text { People, animals, sheets } \\
\text { and handkerchiefs }\end{array}$ & $\begin{array}{l}\text { Man, dog, } \\
\text { spectacles, and cup }\end{array}$ \\
\hline Size compared to normal objects & Normal & Normal & Smaller & Normal \\
\hline Coloured image & Yes & Yes & Yes & Yes \\
\hline Solid/transparent & Solid & Solid & Variable & Solid \\
\hline Movement of images & Yes & No & Yes & Yes \\
\hline $\begin{array}{l}\text { Clarity of image compared to } \\
\text { normal images }\end{array}$ & Clearer & Clearer & Less clear & Same \\
\hline Recurrent image & Yes & No & Yes & No \\
\hline $\begin{array}{l}\text { Always occurs in same region } \\
\text { of visual field }\end{array}$ & No & No & No & No \\
\hline Occurs only in worse seeing eye & No & No & No & No \\
\hline Triggering factors & $\begin{array}{l}\text { Watching television, } \\
\text { eating }\end{array}$ & None & Watching television & None \\
\hline Actions that stop hallucinations & None & Turn on lights & None & Approach object \\
\hline Emotional reaction & Angry & Angry & $\begin{array}{l}\text { Previously worried, } \\
\text { now no reaction }\end{array}$ & No reaction \\
\hline Discussed with family members & Yes & Yes & Yes & No \\
\hline Reaction of family members & Supportive & Supportive & "It's your imagination" & - \\
\hline Discussed with doctor & No & No & Yes & No \\
\hline Reaction of doctor & - & - & $\begin{array}{l}\text { "Laughed and } \\
\text { recommended no further } \\
\text { action" }\end{array}$ & - \\
\hline
\end{tabular}

CBS has been reported in patients with various ocular pathology including age related macular degeneration, ${ }^{911} 12$ diabetic retinopathy, ${ }^{79}{ }^{10}$ glaucoma, ${ }^{19}$ and cataract. ${ }^{10} 20$ Complex visual hallucinations may also occur following certain ophthalmic procedures, including laser photocoagulation for choroidal neovascularisation ${ }^{24}$ and macular translocation. ${ }^{25}$ In fact, one patient in this series reported the onset of CBS following laser iridotomies for bilateral primary angle closure glaucoma and has been separately reported. ${ }^{26}$

Interestingly, the BCVA in the better seeing eye was quite good in three of our patients. Although CBS occurs more commonly in patients with poor visual acuity, ${ }^{10-12}$ Gold et al argued that the diagnosis of CBS does not exclude or require eye pathology. ${ }^{3}$ This view has been supported by findings in other studies, where the BCVA in the better seeing eye of some CBS patients was as good as 20/30. ${ }^{912}$ One reported CBS patient had a BCVA of 20/20 in both eyes. ${ }^{20}$ Holroyd et al suggested a possible explanation might be that while visual disorder is a predisposing factor for visual hallucinations, the degree of visual loss may not be related to the likelihood of developing CBS. ${ }^{9}$ In a review of 64 cases, Schultz et al found that the degree of reduction in visual acuity ranged from slight to total blindness. In some cases, the reduction in vision was the result of a hemianopia with normal acuity in the intact visual field. ${ }^{6}$ This may explain the occurrence of visual hallucinations experienced by our third patient. Although the central visual acuity was good, he had bilateral superior arcuate visual field defects.

The characteristics of CBS hallucinations are quite variable between patients and the hallucinations experienced by our patients exhibited the same wide variety as in previous studies. ${ }^{7}{ }^{11}$

The same three patients who found their hallucinations annoying or frightening voluntarily discussed their symptoms with their family members. Two reported that their relatives were supportive and attributed the hallucinations to their poor eyesight. Since they did not perceive the hallucinations to be a problem, they did not see the need to discuss their symptoms with a doctor. The third patient's relatives concluded that the hallucinations were the result of his imagination. This prompted him to seek the advice of his family physician who "laughed and recommended no further action." The fourth patient was not bothered at all by his hallucinations and did not mention it to anyone.

Not all patients discuss their hallucinations with their doctors. ${ }^{711920}$ In one study, 73\% made no mention of their symptoms to their doctors. ${ }^{7}$ Common reasons included fear of being labelled insane, ${ }^{711} 121820$ of not being taken seriously, ${ }^{7}$ or because they thought that they should not consult a doctor for this. ${ }^{7}$ In one study, of the 16 patients who did discuss their symptoms with a doctor, only one doctor $(6.3 \%)$ made the correct diagnosis. ${ }^{7}$

Other than the initial fear or irritation, which subsided with time, our patients did not experience any extreme emotions as a result of their hallucinations. CBS patients are known to experience various reactions to their hallucinations, from negative emotions ${ }^{912}$ such as anxiety and irritation to positive ones such as joy or amusement. ${ }^{7}$

None of our patients felt the need to hide their symptoms for fear of being labelled a psychiatric case, although, similar 
to other CBS patients, ${ }^{10}{ }^{19}$ three were relieved to hear that CBS is a known condition and affects others. It is important for doctors to be aware that formed visual hallucinations may occur in visually impaired patients. The proportion of visually handicapped individuals in the Asia ranges from $0.4 \%$ to $1.2 \%^{27} 28$ and some of these may experience formed visual hallucinations. Even if they are not bothered emotionally or have come to accept them, it still brings some relief that such symptoms do not indicate psychiatric illness.

The mainstay of treatment of CBS involves recognition, empathy, reassurance, and patient education. ${ }^{12}$ Pharmacotherapy has not universally proved to be useful, ${ }^{12}$ although drugs such as carbamazepine and haloperidol ${ }^{8}$ have been used. Since our patients were not bothered by their symptoms, they were reassured and educated about the condition.

Owing to the small number of CBS cases, we were unable to determine the risk factors for CBS. As more Asian CBS patients are studied, it may be possible to determine if there is any predilection among certain sex or ethnic groups. In summary, our study shows that patients attending a tertiary ophthalmic centre in Singapore have a prevalence rate of CBS which is slightly lower than in comparable studies in nonAsian countries.

\section{Authors' affiliations}

C S H Tan, The Eye Institute at Tan Tock Seng Hospital, National Healthcare Group, Singapore

V S Y Lim, D Y M Ho, E Yeo, Faculty of Medicine, National University of Singapore

B Y Ng, Department of Behavioural Medicine, Singapore General Hospital, Singapore

K G Au Eong, The Eye Institute at Tan Tock Seng Hospital, The Eye Institute at Alexandra Hospital, National Healthcare Group; Department of Ophthalmology, National University of Singapore; and Singapore Eye Research Institute, Singapore

The authors have not received any financial support for this study and have no financial or proprietary interests related to the contents of this manuscript.

Presented in part at the first SERI-ARVO (Singapore Eye Research Institute-Association for Research in Vision and Ophthalmology) Meeting on Research in Vision and Ophthalmology, 6-9 February 2003, Singapore.

\section{APPENDIX}

\section{Questions on hallucinations}

- 1 How long have you seen these images?

- 2 How frequently do you see these images?

- 3 How long does each episode last?

- 4 Has the frequency of hallucinations changed or remained the same since it started?

- 5 Can you describe the images that you see? (If there are more than one, list the common types of hallucinations)

- People

- Animals

- Plants/trees/flowers

- Buildings

- Scenery

- Others (list)

- 6 What is the size of the image compared to normal objects of the same type?

- 7 Does the image have colour or is it black and white?

- 8 Does the image appear solid or can you see though it?

- 9 Does the image ever move?
- 10 How clear is the image compared to normal objects?

- 11 Is this image familiar to you (something that you have seen before)?

- 12 Do you see the same image over and over again?

- 13 Does the image appear in only some parts of your vision or can it appear anywhere?

- 14 Does the image occur only in the eye with poorer vision?

- 15 Is there any situation that makes the image more likely to appear?

- 16 Is there anything that you can do to make the image go away?

- 17 What is your usual reaction to the hallucinations?

- 18 Have you ever told a family member of your hallucinations? If so, what was their reaction? If you did not tell anyone, why not?

- 19 Did you discuss your symptoms with your doctor? If so, what was his reaction? If not, why not?

- 20 Does the image have any personal meaning to you? If yes, elaborate

- 21 Do you feel better now that you know that people who are "normal" (that is, not mad) can sometimes see these images?

\section{REFERENCES}

1 Fernandez A, Lichtshein G, Vieweg WV. The Charles Bonnet syndrome: a review. J Nerv Ment Dis 1997; 185:195-200.

2 Menon GJ, Rahman I, Menon SJ, et al. Complex visual hallucinations in the visually impaired: the Charles Bonnet Syndrome. Surv Ophthalmol 2003;48:58-72.

3 Gold K, Rabins PV. Isolated visual hallucinations and the Charles Bonnet syndrome: a review of the literature and presentation of six cases. Compr Psychiatry 1989;30:90-8.

4 Berrios GE, Brook P. The Charles Bonnet syndrome and the problem of visual perceptual disorders in the elderly. Age Ageing 1982;11:17-23.

5 Cole MG. Charles Bonnet hallucinations: a case series. Can J Psychiatry 1992;37:267-70.

6 Schultz G, Melzack R. The Charles Bonnet syndrome: 'phantom visual images'. Perception 1991;20:809-25.

7 Teunisse RJ, Cruysberg JR, Hoefnagels WH, et al. Visual hallucinations in psychologically normal people: Charles Bonnet's syndrome. Lancet 1996;347:794-7

8 Siatkowski RM, Zimmer B, Rosenberg PR. The Charles Bonnet syndrome. Visual perceptive dysfunction in sensory deprivation. J Clin Neuro-ophthalmol 1990;10:215-18

9 Holroyd S, Rabins PV, Finkelstein D, et al. Visual hallucinations in patients from an ophthalmology clinic and medical clinic population. J Nerv Ment Dis 1994; 182:273-6.

10 Teunisse RJ, Cruysberg JR, Verbeek A, et al. The Charles Bonnet syndrome: a large prospective study in the Netherlands. A study of the prevalence of the Charles Bonnet syndrome and associated factors in 500 patients attending the University Department of Ophthalmology at Nijmegen. Br J Psychiatry 1995; 166:254-7.

11 Holroyd S, Rabins PV, Finkelstein D, et al. Visual hallucinations in patients with macular degeneration. Am J Psychiatry 1992;149:1701-6.

12 Brown GC, Murphy RP. Visual symptoms associated with choroidal neovascularization. Photopsias and the Charles Bonnet syndrome. Arch Ophthalmol 1992;110:1251-6.

13 Cogan DG. Visual hallucinations as release phenomena. Albrecht Von Graefes Arch Klin Exp Ophthalmol 1973;188:139-50.

14 Hartmann PM, Kosko DA, Cohn JA. The Charles Bonnet syndrome (pseudohallucinations) in an AIDS patient with cytomegalovirus retinitis. J Nerv Ment Dis 1995; 183:549-50.

15 Fong SY, Wing YK. Charles Bonnet syndrome with major depression in a Chinese middle-aged man. Aust N Z J Psychiatry 1997;31:769-71.

16 Schwartz TL, Vahgei L. Charles Bonnet syndrome in children. J AAPOS 1998:2:310-3.

17 Mewasingh LD, Kornreich C, Christiaens F, et al. Pediatric phantom vision (Charles Bonnet) syndrome. Pediatr Neurol 2002;26:143-5.

18 Olbrich HM, Engelmeier MP, Pauleikhoff D, et al. Visual hallucinations in ophthalmology. Graefes Arch Clin Exp Ophthalmol 1987;225:217-20.

19 Nesher R, Nesher G, Epstein E, et al. Charles Bonnet syndrome in glaucoma patients with low vision. J Glaucoma 2001;10:396-400.

20 Teunisse RJ, Zitman FG, Raes DC. Clinical evaluation of 14 patients with the Charles Bonnet syndrome (isolated visual hallucinations). Compr Psychiatry 1994:35:70-5

21 Sartorius N. latrogenic stigma of mental illness. BMJ 2002;324:1470.

22 Lai YM, Hong CP, Chee CY. Stigma of mental illness. Singapore Med J 2001;42:111-14. 
23 Teunisse RJ, Cruysberg JR, Hoefnagels WH, et al. Social and psychological characteristics of elderly visually handicapped patients with the Charles Bonnet Syndrome. Compr Psychiatry 1999;40:315-9.

24 Cohen SY, Safran AB, Tadayoni R, et al. Visual hallucinations immediately after macular photocoagulation. Am J Ophthalmol 2000;129:815-16.

25 Au Eong KG, Fujii GY, Ng EW, et al. Transient formed visual hallucinations following macular translocation for subfoveal choroidal neovascularization secondary to age-related macular degeneration. Am J Ophthalmol $2001 ; 131: 664-6$
26 Tan CSH, Yong VKY, Au Eong KG. Onset of Charles Bonnet syndrome (formed visual hallucinations) following bilateral laser peripheral iridotomies. Eye 2004; 18:647-9.

27 See JL, Wong TY, Yeo KT. Trends in the pattern of blindness and major ocular diseases in Singapore and Asia. Ann Acad Med Singapore 1998;27:540-6.

28 Zainal M, Ismail SM, Ropilah AR, et al. Prevalence of blindness and low vision in Malaysian population: results from the National Eye Survey 1996. Br J Ophthalmol 2002;86:951-6.

\section{$\mathrm{ECHO}$}

\section{Gene effects in environmentally determined subgroups}

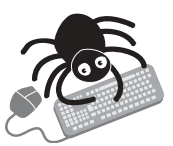

Please visit the Journal of Medical Genetics website [www. jmedgenet. com] for a link to the full text of this article.
$T$ here has been controversy about the usefulness of stratification by environmentally determined subgroups in genetic research. In cancer epidemiology only a few genetic polymorphisms cause a substantial change in risk and many genes involved in the metabolism of mutagens have little or no effect. But the inclusion of environmental measures in genetic studies might reveal environment-gene interactions. Such combined studies have been questioned, however, on the grounds that they are unlikely to increase the power of the genetic study very much. It has been said that the effects of genes in different environmental subgroups are likely to be in the same direction even if varying in size, and this would limit the gain in power. Australian authors have listed several examples to counter this argument.

The first example they give is of the influence of maternal smoking on the effect of the CYPIAl gene on birthweight. The gene controls the metabolism of chemicals in tobacco smoke. When all 741 mothers in a study were considered the incidence of low birthweight was identical $(21.5 \%)$ in mothers with genotype AA and mothers with genotype Aa or aa. Among the 124 maternal smokers however, the incidence of low birthweight was $24 \%$ (AA) $v 45 \%$ (Aa or aa).

The second example concerns the GSTPI glutathione transferase gene, Parkinson's disease, and exposure to pesticides. Among all subjects in one study there was no significant association between the genotype and Parkinson's disease but among subjects exposed to pesticides one polymorphism increased the risk of Parkinson's disease more than fivefold. In the third example they quote a study of the effect of a monoamine oxidase A polymorphism on antisocial behaviour. It has been found that the polymorphism increases the rate of antisocial behaviour only among people who suffered from maltreatment as children. Among people who had not been maltreated in childhood the polymorphism tended to be associated with less antisocial behaviour. Another example of a change in direction of gene effect according to environmental subgroup is the effect of an alcohol dehydrogenase polymorphism on HDL cholesterol concentrations according to level of alcohol consumption. Different polymorphisms may also have different effects on the outcome of a single environmental factor. An example of this is the effect of different $\beta_{2}$ adrenoceptor gene polymorphisms on the risk of obesity at varying levels of carbohydrate consumption.

The authors of this paper conclude that inclusion of environmental data may enhance the search for disease causing genes.

A Journal of Epidemiology and Community Health 2004;75:1178-1180. 